\title{
Structural insights into the ion selectivity of the MgtE channel for
}

\section{$\mathrm{Mg}^{2+}$ over $\mathrm{Ca}^{2+}$}

Xinyu Teng ${ }^{1}$, Danqi Sheng ${ }^{1}$, Jin Wang $^{2}$, Ye Yu ${ }^{2}$, Motoyuki Hattori ${ }^{1}$.

${ }^{1}$ State Key Laboratory of Genetic Engineering, Collaborative Innovation Center of

Genetics and Development, Shanghai Key Laboratory of Bioactive Small Molecules,

Department of Physiology and Neurobiology, School of Life Sciences, Fudan

University, Shanghai 200438, China;

${ }^{2}$ School of Basic Medicine and Clinical Pharmacy, China Pharmaceutical University,

Medical Building, Room 128, 639 Long-Mian Road, Nanjing 200098, China;

Xinyu Teng and Danqi Sheng contributed equally to this work

Correspondence and requests for materials should be addressed to M.H.

(hattorim@fudan.edu.cn). 


\section{Abstract}

$\mathrm{MgtE}$ is a $\mathrm{Mg}^{2+}$-selective ion channel whose orthologs are widely distributed from prokaryotes to eukaryotes, including humans, and play an important role in the maintenance of cellular $\mathrm{Mg}^{2+}$ homeostasis. Previous functional analyses showed that MgtE transports divalent cations with high selectivity for $\mathrm{Mg}^{2+}$ over $\mathrm{Ca}^{2+}$. Whereas the high-resolution structure determination of the MgtE transmembrane (TM) domain in complex with $\mathrm{Mg}^{2+}$ ions revealed a $\mathrm{Mg}^{2+}$ recognition mechanism of $\mathrm{MgtE}$, the previous $\mathrm{Ca}^{2+}$-bound structure of the MgtE TM domain was determined only at moderate resolution (3.2 $\AA$ resolution), which was insufficient to visualize the water molecules coordinated to $\mathrm{Ca}^{2+}$ ions. Thus, the structural basis of the ion selectivity of MgtE for $\mathrm{Mg}^{2+}$ over $\mathrm{Ca}^{2+}$ has remained unclear. Here, we showed that the metal-binding site of the MgtE TM domain binds to $\mathrm{Mg}^{2+} \sim 500$-fold more strongly than $\mathrm{Ca}^{2+}$. We then determined the crystal structure of the MgtE TM domain in complex with $\mathrm{Ca}^{2+}$ ions at a higher resolution (2.5 $\AA$ resolution), allowing us to reveal hexahydrated $\mathrm{Ca}^{2+}$, which is similarly observed in the previously determined $\mathrm{Mg}^{2+}$-bound structure but with extended metal-oxygen bond lengths. Our structural, biochemical, and computational 
bioRxiv preprint doi: https://doi.org/10.1101/2021.12.29.474488; this version posted December 30, 2021. The copyright holder for this preprint (which was not certified by peer review) is the author/funder, who has granted bioRxiv a license to display the preprint in perpetuity. It is made available under aCC-BY-NC-ND 4.0 International license.

analyses provide mechanistic insights into the ion selectivity of $\mathrm{MgtE}$ for $\mathrm{Mg}^{2+}$ over $\mathrm{Ca}^{2+}$. 


\section{Introduction}

$\mathrm{Mg}^{2+}$ ion is a fundamental biological cation implicated in various physiological

functions, such as genomic stability, DNA and RNA folding, and catalysis by hundreds

of enzymes ${ }^{1-3}$. Therefore, cellular $\mathrm{Mg}^{2+}$ homeostasis is vital to all domains of life and

thus is strictly controlled by $\mathrm{Mg}^{2+}$ channels and transporters ${ }^{4-7}$.

MgtE is a bacterial member of the MgtE/SLC41 superfamily of $\mathrm{Mg}^{2+}$ channels and transporters, whose orthologs are widely conserved from bacteria to eukaryotes, including humans ${ }^{8-12} \cdot \mathrm{MgtE}$ is a $\mathrm{Mg}^{2+}$-selective ion channel implicated in cellular $\mathrm{Mg}^{2+}$ homeostasis $^{13,14}$ and is involved in bacterial survival upon exposure to antibiotics ${ }^{15}$. The previous single-channel recording of MgtE from Thermus thermophilus showed high conductance for $\mathrm{Mg}^{2+}$, independent of neither the $\mathrm{pH}$ nor the $\mathrm{Na}^{+}$gradient ${ }^{14,16,17}$, which is consistent with the role of $\mathrm{MgtE}$ as a passive ion channel.

The first MgtE structure in the full-length form showed the homodimeric architecture of MgtE, where each chain consists of the transmembrane (TM) and cytoplasmic domains and a long amphipathic "plug" helix to connect these two domains ${ }^{18}$ (Fig. 1a). The MgtE cytoplasmic domain possesses regulatory $\mathrm{Mg}^{2+}$-binding sites to stabilize the 
closed state in the $\mathrm{Mg}^{2+}$-bound form ${ }^{14,18}$. In other words, the MgtE cytoplasmic domain acts as an intracellular $\mathrm{Mg}^{2+}$ sensor to maintain cellular $\mathrm{Mg}^{2+}$ homeostasis.

The subsequent crystal structures of the MgtE TM domain, in particular the one in complex with $\mathrm{Mg}^{2+}$ ions at high resolution $(2.3 \AA$ resolution), revealed the binding of the fully hydrated $\mathrm{Mg}^{2+}$ ion to the ion selectivity filter in the ion-conducting pore ${ }^{16}$. Nevertheless, since the previously reported MgtE TM domain structure in the presence of $\mathrm{Ca}^{2+}$ ions was determined only at moderate resolution $(3.2 \AA \text { resolution })^{16}$, the mechanism of ion selectivity by MgtE, particularly the specificity for $\mathrm{Mg}^{2+}$ over $\mathrm{Ca}^{2+}$, another essential biological divalent cation, has not yet been fully understood.

Here, we determined the crystal structure of the MgtE TM domain in complex with $\mathrm{Ca}^{2+}$ at a higher resolution of $2.5 \AA$, enabling the visualization of water molecules coordinated to $\mathrm{Ca}^{2+}$ at the ion selectivity filter of MgtE. A combination of structural, biochemical, and computational analyses provided structural insights into the ion selectivity of $\mathrm{MgtE}$ for $\mathrm{Mg}^{2+}$ ions over $\mathrm{Ca}^{2+}$ ions.

\section{Results}




\section{Biochemical cross-linking experiments of $\mathrm{MgtE}$ with $\mathrm{Mg}^{2+}$ and $\mathrm{Ca}^{2+}$}

The previously reported MgtE structures in the presence and absence of $\mathrm{Mg}^{2+}$ ions showed $\mathrm{Mg}^{2+}$-dependent conformational changes in the TM domain, including the TM2 and TM5 helices, which form an ion-conducting pore (Fig. 1b). We verified these structural changes by cross-linking experiments with the cysteine-substituted mutant of MgtE at Leu421 and Thr336 ${ }^{19}$, where the intersubunit distances of $\mathrm{C} \alpha$ atoms between Leu421 and Thr336 were 5.2 and $14.0 \AA$ in the presence and absence of $\mathrm{Mg}^{2+}$ ions, respectively (Fig. 1c).

To estimate how selective the selectivity filter of $\mathrm{MgtE}$ in the $\mathrm{TM}$ domain for $\mathrm{Mg}^{2+}$ over $\mathrm{Ca}^{2+}$ is, using the MgtE T336C/L421C mutant lacking the $\mathrm{N}$ domain (MgtE $\Delta \mathrm{N}$ T336C/L421C) and $\mathrm{Cu}^{2+}$ phenanthroline as a catalyst, we performed biochemical cross-linking experiments in the presence of $\mathrm{Mg}^{2+}$ or $\mathrm{Ca}^{2+}$ at a concentration of gradients (Fig. 2). Whereas MgtE also possesses regulatory $\mathrm{Mg}^{2+}$ binding sites in the cytoplasmic domain, deletion of the $\mathrm{N}$ domain is known to abolish the $\mathrm{Mg}^{2+}$-sensitivity of the cytoplasmic domain ${ }^{14}$. Therefore, in this cross-linking experiment, to estimate the $\mathrm{Mg}^{2+} / \mathrm{Ca}^{2+}$ affinity to the ion selectivity filter in the MgtE $\mathrm{TM}$ domain as exactly as 
possible, we employed the $\Delta \mathrm{N}$ mutant to exclude the influence of $\mathrm{Mg}^{2+}$ binding to the

cytoplasmic domain.

As the concentrations of $\mathrm{Mg}^{2+}$ and $\mathrm{Ca}^{2+}$ increased, the MgtE $\Delta \mathrm{N} \mathrm{T} 336 \mathrm{C} / \mathrm{L} 421 \mathrm{C}$ mutant exhibited a stronger band corresponding to the MgtE dimer (Fig. 2). The estimated $\mathrm{EC}_{50}$ values of $27.7 \pm 3.7 \mu \mathrm{M}$ and $12.2 \pm 1.9 \mathrm{mM}$ for $\mathrm{Mg}^{2+}$ and $\mathrm{Ca}^{2+}$, respectively, indicated the high selectivity of $\mathrm{Mg}^{2+}$ over $\mathrm{Ca}^{2+}$. Notably, the alanine substitution of Asp432 in the TM5 helix, which forms the ion selectivity filter called the M1 site (Fig. 3a), abolished the divalent cation-dependent cross-linking (Fig. 2), indicating that the divalent cation binding to the M1 site indeed induces chemical cross-linking. Overall, these results indicate that the ion selectivity filter of MgtE is highly selective for $\mathrm{Mg}^{2+}$ over $\mathrm{Ca}^{2+}$.

\section{Higher-resolution crystal structure of $\mathrm{MgtE}$ in the $\mathrm{Ca}^{2+}$-bound form}

To obtain a higher-resolution structure of $\mathrm{MgtE}$ in complex with $\mathrm{Ca}^{2+}$ ions, we crystallized the MgtE TM domain in the presence of $\mathrm{Ca}^{2+}$ ions using the lipidic cubic phase (LCP) technique ${ }^{20}$, collected the datasets from a number of microcrystals using 
the ZOO automated data collection system ${ }^{21}$, and merged the datasets from 209 microcrystals using the KAMO automated data processing system ${ }^{22}$. The final datasets yielded a resolution of $2.5 \AA$, higher than before (3.2 $\AA$ ). The newly determined structure of the MgtE TM domain is essentially the same as the previously determined MgtE TM domain (PDB ID: 4U9L), with an RMSD of $0.34 \AA$ for $\mathrm{C} \alpha$ atoms.

In this structure, we observed more detailed features in the electron density maps at the ion selectivity filter (Fig. 3c) than could be observed in the previous, lower-resolution $\mathrm{Ca}^{2+}$-bound structure (Fig. 3b). Among the possible coordination geometries of $\mathrm{Ca}^{2+}$ ions in biology, with a range of water coordination numbers from six to eight ${ }^{23-25}$, the electron densities in our structure adopt an octahedral coordination geometry of $\mathrm{Ca}^{2+}$ ions with six water molecules in the first hydration shell (Fig. 3c). The side chains of Asp432 residues interact with four of six water molecules in the first hydration shell (Fig. 3d). In addition, two extra water molecules in the second hydration shell form hydrogen bonds with the side chain of Asp432 residues and main chain carbonyl oxygen atoms of Ala428 residues (Fig. 3d). These interactions seemingly stabilize $\mathrm{Ca}^{2+}$ ions in the M1 site in the fully hydrated form. The bonding distances 
between $\mathrm{Ca}^{2+}$ ions and coordinated water molecules are 2.4-2.6 $\AA$ (Fig 3D), which is

consistent with the range of Ca-O distances (2.2-2.7 $\AA$ ) in previously reported crystal structures ${ }^{3}$.

Notably, in the previously reported $\mathrm{Mg}^{2+}$-bound structure (Fig. 3e), $\mathrm{Mg}^{2+}$ also adopts a very similar octahedral coordination geometry to that observed in the present $\mathrm{Ca}^{2+}$-bound structure (Fig. 3d) but with shorter bonding distances between $\mathrm{Mg}^{2+}$ and water molecules of 2.0-2.2 $\AA$, which is also consistent with the typical Mg-O distance in previously reported crystal structures ${ }^{3}$.

\section{MD simulations}

To further examine $\mathrm{Mg}^{2+}$ and $\mathrm{Ca}^{2+}$ recognition by the $\mathrm{M} 1$ site of $\mathrm{MgtE}$, we performed MD simulations based on the current $\mathrm{Ca}^{2+}$-bound crystal structure together with the previously reported $\mathrm{Mg}^{2+}$-bound structure (Fig. 4). The overall structures were mostly stable during the $1-\mu$ s simulations starting from the MgtE structure embedded in the POPC lipid bilayer (Fig. 4a). Both the $\mathrm{Mg}^{2+}$ ion and $\mathrm{Ca}^{2+}$ ion were stably bound to the M1 site with all six water molecules in the fully hydrated state. Importantly, the 
distances between $\mathrm{Mg}^{2+}$ and water molecules and between $\mathrm{Ca}^{2+}$ and water molecules were stable during the simulations, whereas $\mathrm{Ca}^{2+}$ maintained a longer distance from water molecules than $\mathrm{Mg}^{2+}$ (Fig. $\left.\mathbf{4 b}, \mathbf{c}, \mathbf{d}\right)$.

These results further support the insights from the crystal structures that the M1 site of MgtE can accommodate both $\mathrm{Mg}^{2+}$ and $\mathrm{Ca}^{2+}$ in the octahedral coordination geometry with six water molecules but with longer bonding distances between $\mathrm{Ca}^{2+}$ and water molecules.

\section{Discussion}

$\mathrm{Mg}^{2+}$ and $\mathrm{Ca}^{2+}$ are fundamental divalent cations for life. However, relatively little is known about the selectivity mechanisms by which ion channels and transporters discriminate them. In this work, we showed by biochemical cross-linking that the M1 site of the MgtE TM domain is highly selective for $\mathrm{Mg}^{2+}$ over $\mathrm{Ca}^{2+}$ (Fig. 2). The improved crystal structure of the MgtE TM domain in complex with $\mathrm{Ca}^{2+}$ together with the MD simulations suggested that the M1 site recognizes $\mathrm{Ca}^{2+}$ in an octahedral coordination geometry with six water molecules, similar to that observed in the 
previously determined $\mathrm{Mg}^{2+}$-bound structure, but with longer metal-water bond lengths

(Figs. 3 and 4).

Based on these results, we discuss the ion selectivity mechanism of $\mathrm{MgtE}$ for $\mathrm{Mg}^{2+}$ over $\mathrm{Ca}^{2+}$. First, the coordination number can be from six to eight for $\mathrm{Ca}^{2+}$, but seven is most common in aqueous solution ${ }^{23-26}$. Consistently, the $\mathrm{Ca}^{2+}$ ATPase pump and $\mathrm{Na}^{+} / \mathrm{Ca}^{2+}$ exchanger also recognize $\mathrm{Ca}^{2+}$ ions with a coordination number of $\operatorname{seven}^{27,28}$, which directly explains their ion selectivity for $\mathrm{Ca}^{2+}$ over $\mathrm{Mg}^{2+}$, since $\mathrm{Mg}^{2+}$ ions have a strict octahedral coordination with six water molecules. On the other hand, in the case of $\mathrm{MgtE}$, the $\mathrm{M} 1$ site recognizes $\mathrm{Ca}^{2+}$ ions in the octahedral coordination geometry with six water molecules (Fig. 3). Since $\mathrm{Ca}^{2+}$ is estimated to have a coordination number from six to eight and since the coordination number of seven is preferable, a loss of coordination would occur when $\mathrm{Ca}^{2+}$ takes on an octahedral coordination number in the M1 site of MgtE. In other words. $\mathrm{Ca}^{2+}$ has to be forced into a lower coordination mode when bound to the M1 site of MgtE. This may explain the selectivity of $\mathrm{MgtE}$ for $\mathrm{Mg}^{2+}$ over $\mathrm{Ca}^{2+}$.

Overall, our structural, biochemical and computational analyses provide insights into 
the selectivity of $\mathrm{MgtE}$ for $\mathrm{Mg}^{2+}$ over $\mathrm{Ca}^{2+}$.

\section{Methods}

\section{Expression and purification}

The MgtE $\Delta \mathrm{N}$ domain mutant gene from T. thermophilus (residues 130-450) was

subcloned into a pET28a vector containing an N-terminal hexahistidine tag and a thrombin cleavage site. The human rhinovirus 3C (HRV3C) protease cleavage site was inserted between residues Asp267 and Val268 at the loop region between the cytoplasmic domain and TM domain. The protein expression and purification of MgtE were similarly performed as described previously ${ }^{16,18,19}$. MgtE protein was overexpressed in E. coli Rosetta (DE3) cells in LB medium containing $30 \mu \mathrm{g} / \mathrm{ml}$ kanamycin at $37{ }^{\circ} \mathrm{C}$ by adding $0.5 \mathrm{mM}$ isopropyl- $\beta$-D-thiogalactoside (IPTG) at an $\mathrm{OD}_{600}$ of $\sim 0.5$, and then $E$. coli cells were further cultured at $18{ }^{\circ} \mathrm{C}$ for 16 hours. The $E$. coli cells were harvested by centrifugation $(6,000 \times \mathrm{g}, 15$ minutes $)$ and then resuspended in buffer $\mathrm{H}[150 \mathrm{mM} \mathrm{NaCl}, 50 \mathrm{mM}$ HEPES $(\mathrm{pH} 7.0)$ and $0.5 \mathrm{mM}$ phenylmethanesulfonyl fluoride (PMSF)]. All purification procedures were performed 
at $4{ }^{\circ} \mathrm{C}$. The $E$. coli cells were disrupted with a microfluidizer. After centrifugation

$(20,000 \times \mathrm{g}, 30$ minutes $)$, the supernatants were collected and subjected to ultracentrifugation $(200,000 \times \mathrm{g}, 1$ hour $)$. The membrane fraction from ultracentrifugation was then solubilized with buffer $\mathrm{S}$ [300 mM NaCl, $50 \mathrm{mM}$ HEPES (pH 7.0), 2\% (w/v) n-dodecyl-beta-d-maltopyranoside (DDM) (Anatrace, USA) and 0.5 mM PMSF] for 2 hours. The solubilization fraction was loaded onto a Ni-NTA column preequilibrated with buffer A [300 mM NaCl, $50 \mathrm{mM}$ HEPES (pH 7.0) and 0.05\% (w/v) DDM] containing $20 \mathrm{mM}$ imidazole, mixed, and incubated for 1 hour. The Ni-NTA column was washed with buffer A containing $50 \mathrm{mM}$ imidazole, and the MgtE protein was eluted with buffer A containing $300 \mathrm{mM}$ imidazole.

To cleave the HRV3C protease cleavage site, the eluate was mixed with Ni-NTA beads preequilibrated in buffer B and His-tagged HRV3C protease and then dialyzed against buffer B overnight. The sample was reloaded on a column, and the flow-through fractions containing the MgtE TM domain protein were concentrated using an Amicon Ultra $50 \mathrm{~K}$ filter (Merck Millipore, USA). After concentration, the sample was injected into a Superdex 200 10/300 size-exclusion column (GE Healthcare, USA) equilibrated 
with buffer C [25 mM HEPES (pH 7.0), $150 \mathrm{mM} \mathrm{NaCl}$ and $0.025 \%$ (w/v) DDM] for size-exclusion chromatography (SEC). The peak fractions containing the MgtE TM domain protein were collected and concentrated to $10 \mathrm{mg} / \mathrm{ml}$ using an Amicon Ultra 50 K filter (Merck Millipore, USA) for crystallization.

For the MgtE $\Delta \mathrm{N}$ T336C/L421C and MgtE $\Delta \mathrm{N}$ T336C/L421C/D432A cysteine mutants, the protein expression and preparation of the membrane fractions were performed similarly to the methods described above. The membrane fractions were solubilized with buffer D [50 mM HEPES (pH 7.0), $150 \mathrm{mM} \mathrm{NaCl,} \mathrm{2 \%} \mathrm{DDM,} 20 \mathrm{mM}$ imidazole, 1 mM PMSF, $1 \mathrm{mM} \beta$-mercaptoethanol ( $\beta$-ME)] for 2 hours. Then, insoluble materials were removed by ultracentrifugation $(200,000 \times \mathrm{g}, 1$ hour $)$. The supernatant was mixed with Ni-NTA resin preequilibrated with buffer D, incubated for 1 hour, washed with buffer E [50 mM HEPES (pH 7.0), $150 \mathrm{mM} \mathrm{NaCl}, 0.05 \%$ DDM, $50 \mathrm{mM}$ imidazole, 1 $\mathrm{mM} \beta-\mathrm{ME}$, and then eluted with buffer $\mathrm{F}$ [50 mM HEPES (pH 7.0), $150 \mathrm{mM} \mathrm{NaCl}$, 0.05\% DDM, $300 \mathrm{mM}$ imidazole, $1 \mathrm{mM} \beta-\mathrm{ME}]$. The eluted MgtE proteins were dialyzed in buffer G [50 mM HEPES (pH 7.0), $150 \mathrm{mM} \mathrm{NaCl}, 0.05 \%$ DDM, $20 \mathrm{mM}$ dithiothreitol (DTT)] overnight and applied to a Superdex 200 10/300 size-exclusion 
column equilibrated with buffer $\mathrm{H}$ [20 mM HEPES (pH 7.0), $150 \mathrm{mM} \mathrm{NaCl}, 0.03 \%$

DDM] for SEC. The peak fractions were concentrated to $0.5 \mathrm{mg} / \mathrm{ml}$ using an Amicon

Ultra 50K filter.

\section{Crystallization}

Before crystallization, the purified MgtE TM domain protein was mixed with $\mathrm{CaCl}_{2}$ at a

final concentration of $100 \mathrm{mM}$ and incubated on ice for 30 minutes. The protein was

then mixed with monoolein (NU-CHEK, USA) at a ratio of 2:3 (w:w) in a twin syringe

to generate lipidic cubic phase $(\mathrm{LCP})^{20}$. For crystallization, a Gryphon LCP crystallization robot (Art Robbins Instruments, USA) was employed to dispense $50 \mathrm{nl}$ of LCP drops onto a 96-well sandwich plate and to overlay $700 \mathrm{nl}$ reservoir solutions.

Crystals appeared at $18{ }^{\circ} \mathrm{C}$ after one week in the reservoir solution containing $30 \%$ (w/v) polyethylene glycol (PEG) 400, 100 mM HEPES (pH 7.5), and $100 \mathrm{mM} \mathrm{NaSCN}$.

\section{X-ray data collection and structure determination}


X-ray diffraction data were collected at the BL32XU beamline at SPring-8 (Harima,

Japan) using the ZOO automatic data collection system ${ }^{21}$ and processed with $\mathrm{KAMO}^{22}$ and $\mathrm{XDS}^{29}$. The structure of the MgtE TM domain in complex with $\mathrm{Ca}^{2+}$ (residues 271-448 for chains A and B) was determined by molecular replacement with Phaser ${ }^{30}$ using the $\mathrm{Mg}^{2+}$-bound MgtE TM domain structure (PDB ID: 4U9L). The atomic model was then manually built using COOT $^{31}$ and refined with PHENIX ${ }^{32}$. The Ramachandran plots were calculated using MolProbity ${ }^{33}$. X-ray data collection and refinement statistics are summarized in Table 1. All structure figures were generated using PyMOL (https://pymol.org/).

\section{Biochemical cross-linking}

Biochemical cross-linking experiments were performed as described previously ${ }^{19}$. First,

$4 \mu \mathrm{l}$ of MgtE protein at $0.5 \mathrm{mg} / \mathrm{ml}$ was mixed with $0.5 \mu \mathrm{l}$ of EDTA at a final concentration of $5 \mathrm{mM}, \mathrm{MgCl}_{2}$ or $\mathrm{CaCl}_{2}$, at appropriate concentrations, respectively, incubated on ice for $30 \mathrm{~min}$, then mixed with $0.5 \mu \mathrm{L}$ of $10 \mathrm{mM}$ freshly prepared $\mathrm{Cu}^{2+}$ bis-1,10-phenanthroline (with molar ratio 1:3) to react on ice for another $30 \mathrm{~min}$. 
Samples were analyzed by SDS-PAGE in nonreducing conditions. Experiments were repeated six times. SDS-PAGE gels were quantified by ImageJ (NIH, USA), and the quantified data were fitted to a nonlinear curve by Origin (OriginLab, USA).

\section{Molecular dynamics simulations}

Molecular dynamics (MD) simulations were performed using 'Desmond' software ${ }^{34}$.

The initial positioning of MgtE in the

1-palmitoyl-2-oleoyl-sn-glycero-3-phosphocholine (POPC) membrane was obtained

from the OPM database ${ }^{35}$. The POPC membrane-bound structures were built using a simple point charged water model (SPC) in an orthorhombic box with dimensions of 10

$\AA \times 10 \AA \times 10 \AA$. To maintain balance and neutralize the system, counter ions $\left(\mathrm{Na}^{+}\right.$or $\left.\mathrm{Cl}^{-}\right)$were added. $\mathrm{NaCl}(150 \mathrm{mM})$ was added to the simulation box to represent background salt under physiological conditions. Prior to MD simulation, the DESMOND default relaxation protocol was applied to each system. (1) 100 ps simulations in the NVT ensemble with Brownian kinetics using a temperature of $10 \mathrm{~K}$ with solute heavy atoms constrained; (2) 12 ps simulations in the NVT ensemble using 
a Berendsen thermostat with a temperature of $10 \mathrm{~K}$ and small-time steps with solute heavy atoms constrained; (3) 12 ps simulations in the NPT ensemble using a Berendsen thermostat and barostat for $12 \mathrm{ps}$ simulations at $10 \mathrm{~K}$ and 1 atm, with solute heavy atoms constrained; (4) 12 ps simulations in the NPT ensemble using a Berendsen thermostat and barostat at $300 \mathrm{~K}$ and 1 atm, with solute heavy atoms constrained; (5) 24 ps simulations in the NPT ensemble using a Berendsen thermostat and barostat at $300 \mathrm{~K}$ and $1 \mathrm{~atm}$ without constraint. After equilibration, the MD simulations were performed for $1000 \mathrm{~ns}$. Long-range electrostatic interactions were computed using a smooth particle mesh Ewald method. The trajectory recording interval was set to $200 \mathrm{ps}$, and other default parameters of DESMOND were used during MD simulation runs. All simulations used the all-atom OPLS_2005 force field ${ }^{36,37}$, which was used for the protein ions, and ligand molecules, for proteins, ions, lipids and SPC waters. All simulations were run on a DELL T7920 graphic working station (with an NVIDA Tesla K40C-GPU). Analysis and visualization were performed on a 12-CPU CORE DELL T3610 graphic working station. 


\section{Statistics and reproducibility}

The biochemical cross-linking experiments in Fig. 2 were repeated six times. Error bars represent the standard error of the mean. X-ray data collection and refinement statistics are summarized in Table $\mathbf{1}$.

\section{Data availability}

The atomic coordinates and structure factors of MgtE were deposited in the Protein Data Bank (PDB ID: 7F7U). All SDS-PAGE gels can be found in Supplementary Figs. 1-4. All materials are available from the authors upon reasonable request.

\section{References}

1 Hartwig, A. Role of magnesium in genomic stability. Mutation research $\mathbf{4 7 5}$, 113-121, (2001).

2 Cowan, J. A. Structural and catalytic chemistry of magnesium-dependent enzymes. Biometals : an international journal on the role of metal ions in biology, biochemistry, and medicine 15, 225-235, (2002).

3 Maguire, M. E. \& Cowan, J. A. Magnesium chemistry and biochemistry. Biometals : an international journal on the role of metal ions in biology, biochemistry, and medicine 15, 203-210, (2002).

4 Alexander, R. T., Hoenderop, J. G. \& Bindels, R. J. Molecular determinants of magnesium homeostasis: insights from human disease. J Am Soc Nephrol 19, 1451-1458, (2008).

5 Groisman, E. A. et al. Bacterial $\mathrm{Mg}^{2+}$ homeostasis, transport, and virulence. 
Annual review of genetics 47, 625-646, (2013).

6 Romani, A. M. Cellular magnesium homeostasis. Archives of biochemistry and biophysics 512, 1-23, (2011).

7 Moomaw, A. S. \& Maguire, M. E. The unique nature of $\mathrm{mg}^{2+}$ channels. Physiology 23, 275-285, (2008).

8 Smith, R. L., Thompson, L. J. \& Maguire, M. E. Cloning and characterization of MgtE, a putative new class of $\mathrm{Mg}^{2+}$ transporter from Bacillus firmus OF4. $J$ Bacteriol 177, 1233-1238 (1995).

9 Townsend, D. E. et al. Cloning of the mgtE $\mathrm{Mg}^{2+}$ transporter from Providencia stuartii and the distribution of mgtE in gram-negative and gram-positive bacteria. J Bacteriol 177, 5350-5354 (1995).

10 Goytain, A. \& Quamme, G. A. Functional characterization of human SLC41A1,

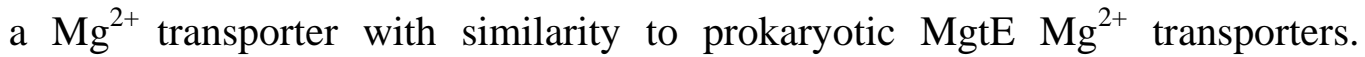
Physiological genomics 21, 337-342, (2005).

11 Sahni, J. \& Scharenberg, A. M. The SLC41 family of MgtE-like magnesium transporters. Molecular aspects of medicine 34, 620-628, (2013).

12 Schweigel-Röntgen, M. \& Kolisek, M. SLC41 transporters--molecular identification and functional role. Current topics in membranes 73, 383-410, (2014).

13 Dann, C. E., 3rd et al. Structure and mechanism of a metal-sensing regulatory RNA. Cell 130, 878-892, (2007).

14 Hattori, M. et al. $\mathrm{Mg}^{2+}$-dependent gating of bacterial MgtE channel underlies $\mathrm{Mg}^{2+}$ homeostasis. The EMBO journal 28, 3602-3612, (2009).

15 Lee, D. D. et al. Magnesium Flux Modulates Ribosomes to Increase Bacterial Survival. Cell 177, 352-360.e313, (2019).

16 Takeda, H. et al. Structural basis for ion selectivity revealed by high-resolution crystal structure of $\mathrm{Mg}^{2+}$ channel MgtE. Nature communications 5, 5374, (2014).

17 Tomita, A. et al. ATP-dependent modulation of $\mathrm{MgtE}$ in $\mathrm{Mg}^{2+}$ homeostasis. Nature communications 8, 148, (2017).

18 Hattori, M., Tanaka, Y., Fukai, S., Ishitani, R. \& Nureki, O. Crystal structure of the MgtE $\mathrm{Mg}^{2+}$ transporter. Nature 448, 1072-1075, (2007).

19 Jin, F. et al. The structure of MgtE in the absence of magnesium provides new 
insights into channel gating. PLoS biology 19, e3001231, (2021).

20 Cherezov, V. Lipidic cubic phase technologies for membrane protein structural studies. Current opinion in structural biology 21, 559-566, (2011).

21 Hirata, K. et al. ZOO: an automatic data-collection system for high-throughput structure analysis in protein microcrystallography. Acta crystallographica. Section D, Structural biology 75, 138-150, (2019).

22 Yamashita, K., Hirata, K. \& Yamamoto, M. KAMO: towards automated data processing for microcrystals. Acta crystallographica. Section D, Structural biology 74, 441-449, (2018).

23 Jalilehvand, F. et al. Hydration of the Calcium Ion. An EXAFS, Large-Angle X-ray Scattering, and Molecular Dynamics Simulation Study. Journal of the American Chemical Society 123, 431-441, (2001).

24 Pavlov, M., Siegbahn, P. E. M. \& Sandström, M. Hydration of Beryllium, Magnesium, Calcium, and Zinc Ions Using Density Functional Theory. The Journal of Physical Chemistry A 102, 219-228, (1998).

25 Katz, A. K., Glusker, J. P., Beebe, S. A. \& Bock, C. W. Calcium Ion Coordination: A Comparison with That of Beryllium, Magnesium, and Zinc. Journal of the American Chemical Society 118, 5752-5763, (1996).

26 Bogatko, S. et al. The aqueous $\mathrm{Ca}^{2+}$ system, in comparison with $\mathrm{Zn}^{2+}, \mathrm{Fe}^{3+}$, and $\mathrm{Al}^{3+}$ : an ab initio molecular dynamics study. Chemistry (Weinheim an der Bergstrasse, Germany) 19, 3047-3060, (2013).

27 Liao, J. et al. Structural insight into the ion-exchange mechanism of the sodium/calcium exchanger. Science (New York, N.Y.) 335, 686-690, (2012).

28 Toyoshima, C., Nakasako, M., Nomura, H. \& Ogawa, H. Crystal structure of the calcium pump of sarcoplasmic reticulum at 2.6 A resolution. Nature 405, 647-655, (2000).

29 Kabsch, W. XDS. Acta Crystallographica Section D 66, 125-132 (2010).

30 McCoy, A. J. et al. Phaser crystallographic software. Journal of applied crystallography 40, 658-674, (2007).

31 Emsley, P., Lohkamp, B., Scott, W. G. \& Cowtan, K. Features and development of Coot. Acta crystallographica. Section D, Biological crystallography 66, 486-501, (2010).

32 Liebschner, D. et al. Macromolecular structure determination using X-rays, 
neutrons and electrons: recent developments in Phenix. Acta Crystallographica Section D 75, 861-877 (2019).

33 Chen, V. B. et al. MolProbity: all-atom structure validation for macromolecular crystallography. Acta crystallographica. Section D, Biological crystallography 66, 12-21, (2010).

34 Shaw, D. E. A fast, scalable method for the parallel evaluation of distance-limited pairwise particle interactions. Journal of computational chemistry 26, 1318-1328, (2005).

35 Lomize, M. A., Pogozheva, I. D., Joo, H., Mosberg, H. I. \& Lomize, A. L. OPM database and PPM web server: resources for positioning of proteins in membranes. Nucleic acids research 40, D370-376, (2012).

36 Kaminski, G. A., Friesner, R. A., Tirado-Rives, J. \& Jorgensen, W. L. Evaluation and Reparametrization of the OPLS-AA Force Field for Proteins via Comparison with Accurate Quantum Chemical Calculations on Peptides. The Journal of Physical Chemistry B 105, 6474-6487, (2001).

37 Jorgensen, W. L., Maxwell, D. S. \& Tirado-Rives, J. Development and Testing of the OPLS All-Atom Force Field on Conformational Energetics and Properties of Organic Liquids. Journal of the American Chemical Society 118, 11225-11236, (1996).

\section{Acknowledgments}

We thank the staff from the BL32XU and BL41XU beamlines at SPring- 8 and from

BL17U1 at Shanghai Synchrotron Radiation Facility (SSRF) for assistance during X-ray data collection. The diffraction experiments were performed at SPring-8 BL32XU and BL41XU (Proposal Nos. 2019A2514 and 2020A2524) and at SSRF 
BL17U1 (Proposal No. 2018-SSRF-PT-004257). This work was supported by funding

from the Ministry of Science and Technology of China (National Key R\&D Program of

China: 2016YFA0502800) to M.H. and from the National Natural Science Foundation

of China (32071234) to M.H. This work was also supported by the Innovative Research

Team of High-level Local Universities in Shanghai and a key laboratory program of the

Education Commission of Shanghai Municipality (ZDSYS14005) and by the Open

Research Fund of State Key Laboratory of Genetic Engineering, Fudan University (No.

SKLGE-2105).

\section{Author contributions}

X.T. and D.S. purified and crystallized the MgtE TM domain and determined the

$\mathrm{Ca}^{2+}$-bound structure of MgtE. X.T. performed the biochemical cross-linking

experiments. J.W. and Y.Y. performed MD simulations. X.T., D.S. and M.H. wrote the

manuscript. M.H. supervised the research. All authors discussed the manuscript. 


\section{Competing interests}

The authors declare no competing interests.

\section{Figure legends}

\section{Figure $1 \mathrm{Mg}^{2+}$-dependent cytoplasmic pore-closure motions}

(A) T. thermophilus MgtE dimer structure in complex with $\mathrm{Mg}^{2+}$ ions (PDB ID:2ZY9), viewed parallel to the membrane. (B, C) The $\mathrm{Mg}^{2+}$-free $\mathrm{MgtE} \mathrm{TM}$ domain dimer structure (PDB ID: 6LBH) superposed on the $\mathrm{Mg}^{2+}$-bound $\mathrm{MgtE}$ TM domain dimer using the $\mathrm{C} \alpha$ positions. The overall structure of the TM domain dimer (B) and close-up view of the dimer interface on the cytoplasmic side $(\mathbf{C})$ are shown. The structural features of the $\mathrm{Mg}^{2+}$-bound structure in chain A (N, CBS and TM domains and plug helix) are colored blue, green, salmon and yellow, respectively. Chain B is colored cyan. $\mathrm{Mg}^{2+}$ ions are colored as magenta spheres. $\mathrm{Mg}^{2+}$-free $\mathrm{MgtE}$ is colored gray. The black arrows denote the structural transitions from the $\mathrm{Mg}^{2+}$-bound state to the $\mathrm{Mg}^{2+}$-free state (B). Dashed lines denote the C $\alpha$ distances between Thr336 and Leu421 residues.

\section{Figure 2 Biochemical cross-linking experiments of $\mathrm{MgtE}$ with $\mathrm{Mg}^{2+}$ and $\mathrm{Ca}^{2+}$}

(A-D) Representative SDS-PAGE gels from biochemical cross-linking experiments of the MgtE $\Delta \mathrm{N}$ domain double cysteine mutant T336C/L421C with $\mathrm{Mg}^{2+}(\mathbf{A}), \mathrm{Ca}^{2+}(\mathbf{B})$, $\mathrm{Mg}^{2+}$ and the D432A mutation $(\mathbf{C})$, and $\mathrm{Ca}^{2+}$ and the D432A mutation (D). (E-H) 
Densitometric quantification of SDS-PAGE band intensities of the MgtE dimer (black) and monomer (red) with $\mathrm{Mg}^{2+}(\mathbf{E}), \mathrm{Ca}^{2+}(\mathbf{F}), \mathrm{Mg}^{2+}$ and the D432A mutation $(\mathbf{G})$ and of $\mathrm{Ca}^{2+}$ and the D432A mutation $(\mathbf{H})$ for sigmoidal curve fitting. Experiments were performed six times. Error bars represent SEM. All SDS-PAGE gels can be found in Supplementary Figs. 1-4.

\section{Figure 3 Ion selectivity filter}

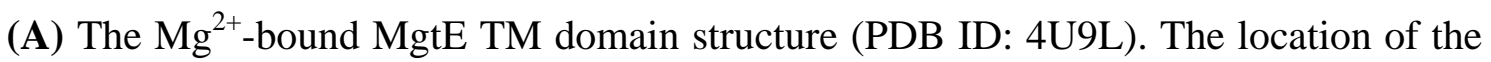
ion selectivity filter (M1 site) is marked. (B, C, D) A close-up view of the M1 site in the $\mathrm{Ca}^{2+}$-bound MgtE TM domain structures, previously determined at $3.2 \AA$ resolution (PDB ID: 4WIB) (B) and determined at $2.5 \AA$ resolution in this study in a stereo view. (C, D). (E) A close-up view of the M1 site in the $\mathrm{Mg}^{2+}$-bound MgtE TM domain structure (PDB ID: 4U9L). The POLDER-OMIT maps for $\mathrm{Ca}^{2+}$ and associated water molecules are shown in blue mesh (contoured at $3.0 \sigma)(\mathbf{B}, \mathbf{C})$. The coloring scheme is the same as in Fig. 1. Amino acid residues at the metal binding site are shown in stick representation. $\mathrm{Mg}^{2+}, \mathrm{Ca}^{2+}$ and water molecules are shown as magenta, green and red spheres, respectively. Dashed lines indicate hydrogen bonds, and associated numbers show the water-metal distances $(\AA)$.

\section{Figure 4 MD simulations}

(A) Structural deviations from the MgtE $\mathrm{TM}$ domain structure during 1- $\mu \mathrm{s} \mathrm{MD}$ simulations with $\mathrm{Mg}^{2+}$ or $\mathrm{Ca}^{2+}$ ions. (B) A close-up view of the metal binding site in the 
MgtE TM domain structure with the fully hydrated $\mathrm{Mg}^{2+}$ ion (PDB ID: 4U9L).

Alphabetical labels of the water molecules correspond to those in Fig. 4c, d. (C, D)

Water-metal distances between $\mathrm{Mg}^{2+}$ and coordinated water molecules $(\mathbf{C})$ and between

$\mathrm{Ca}^{2+}$ and coordinated water molecules (D) during 1- $\mu$ s -MD simulations.

Table $1 \mathrm{X}$-ray data collection and refinement statistics. 
bioRxiv preprint doi: https://doi.org/10.1101/2021.12.29.474488; this version posted December 30, 2021. The copyright holder for this preprint (which was not certified by peer review) is the author/funder, who has granted bioRxiv a license to display the preprint in

A

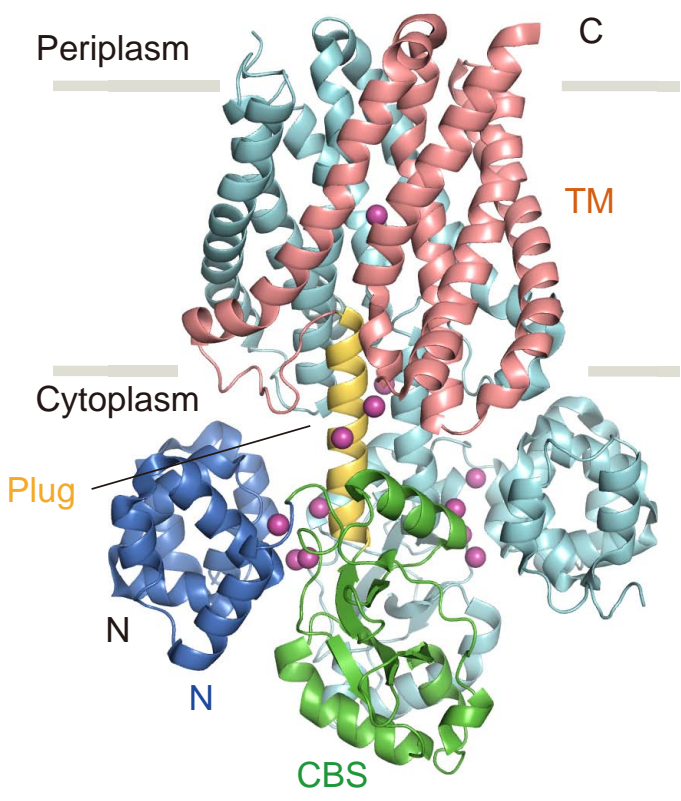

B
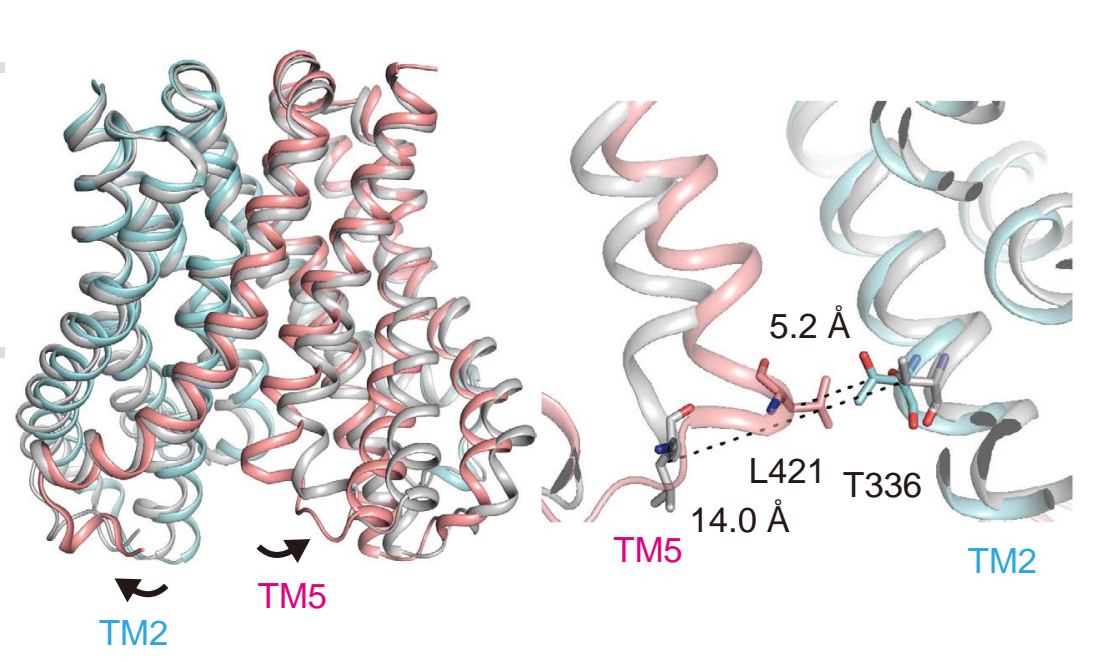

TM2
C
Figure 1 


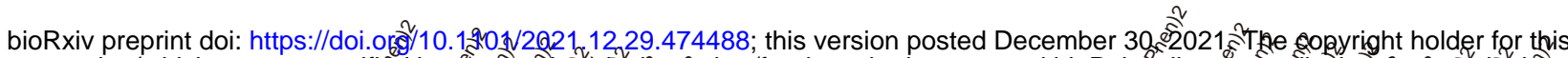

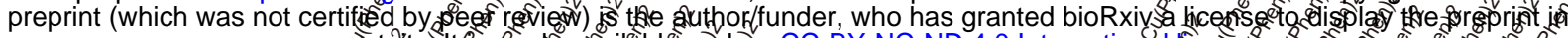
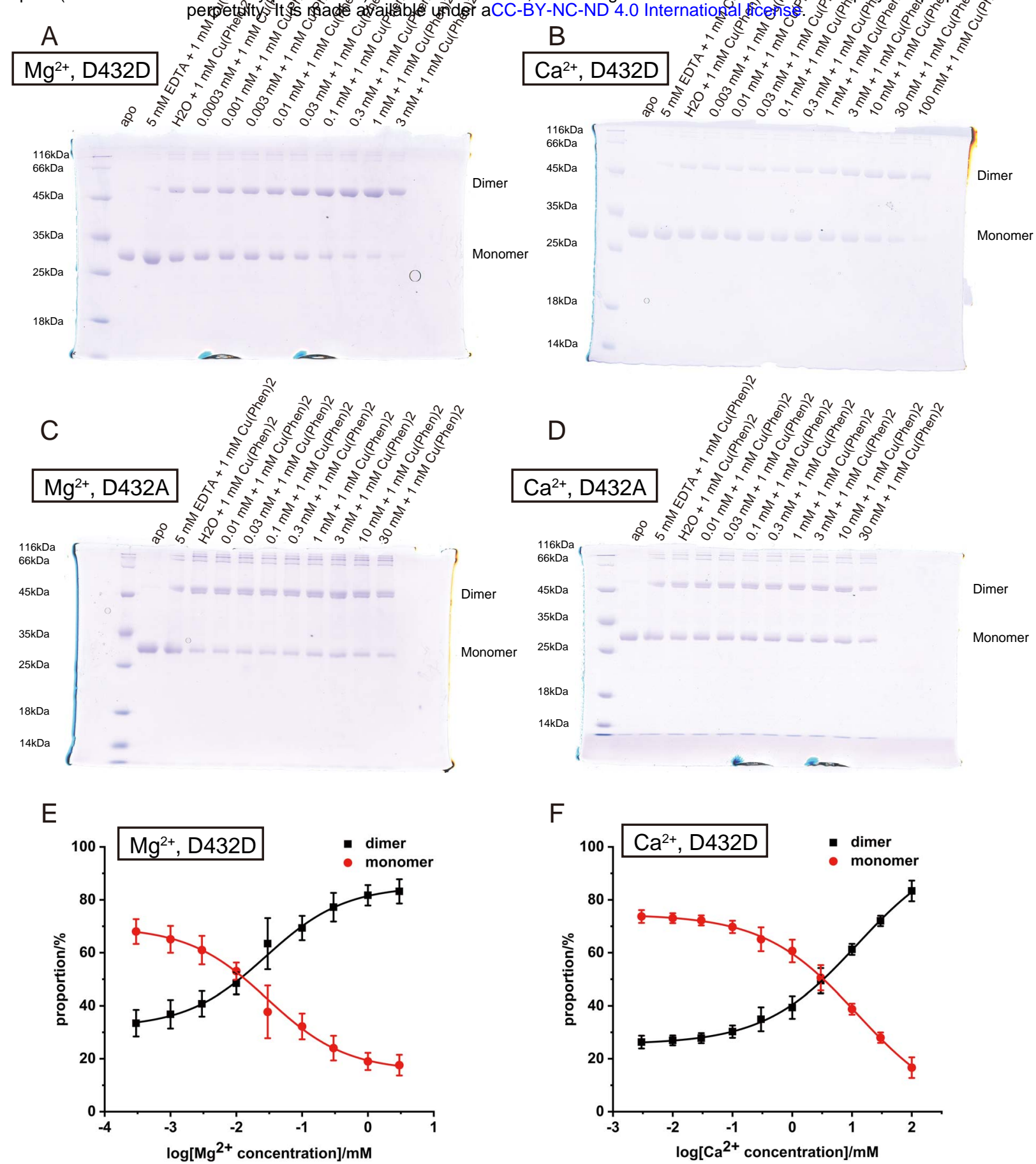

G

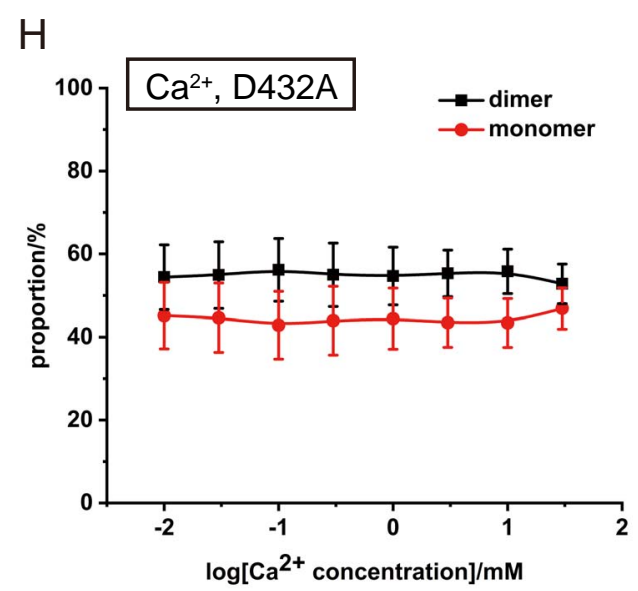

Figure 2 
A

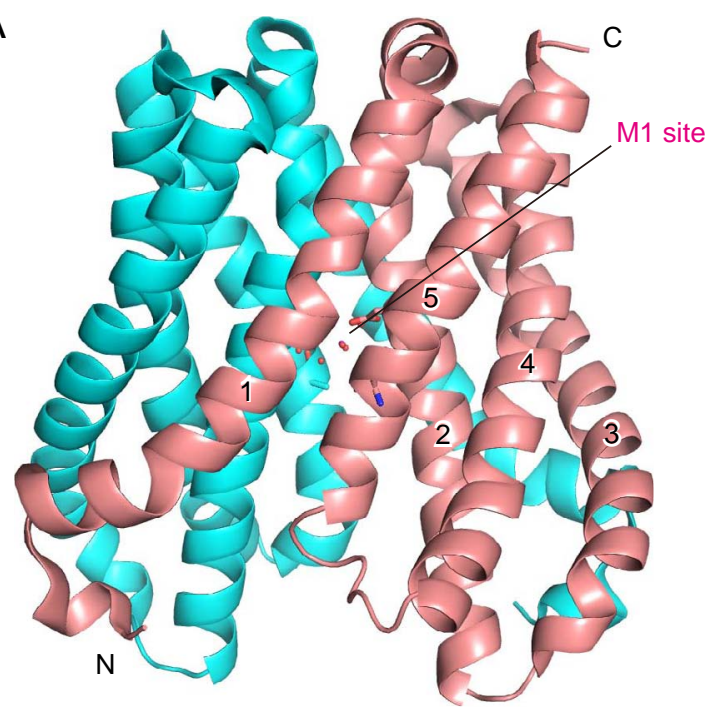

B
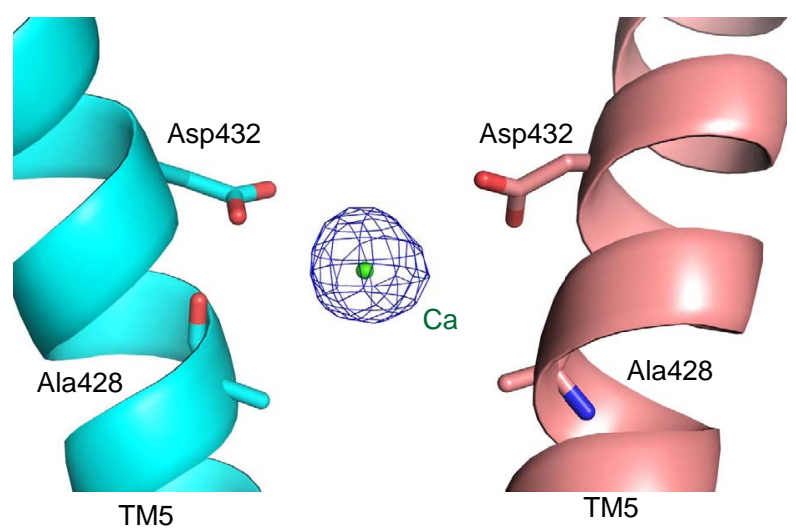

C

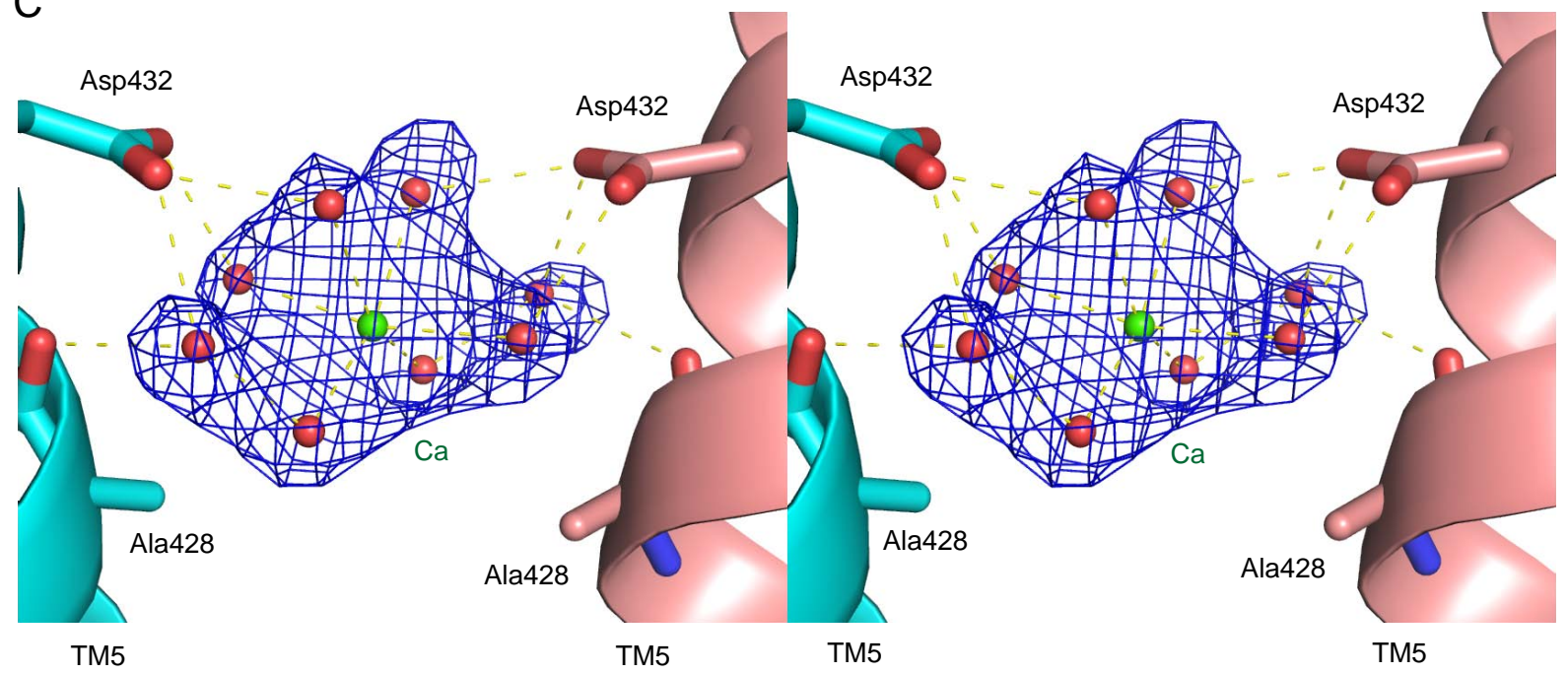

$\mathrm{D}$

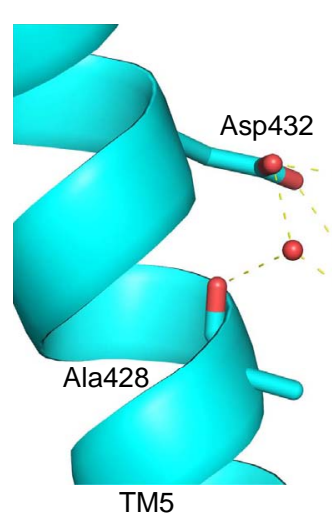

$\mathrm{E}$

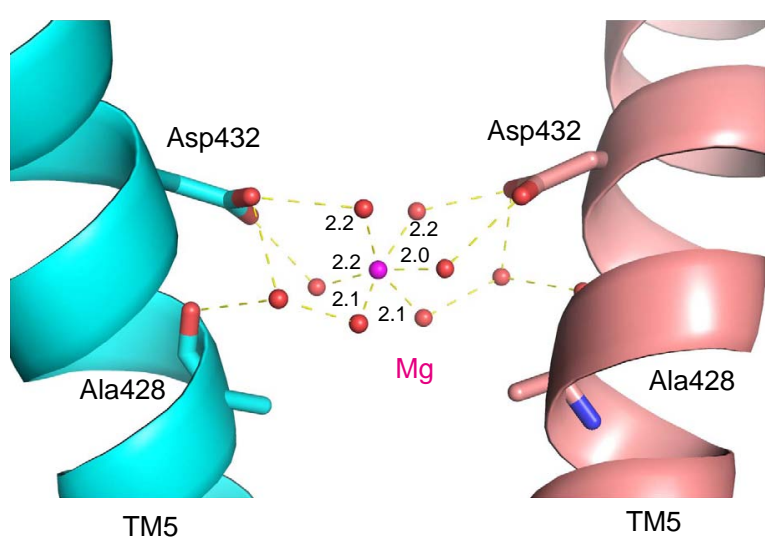

Figure 3 
bioRxiv preprint doi: https://doi.org/10.1101/2021.12.29.474488; this version posted December 30, 2021. The copyright holder for this preprint (which was not certified by peer review) is the author/funder, who has granted bioRxiv a license to display the preprint in

A

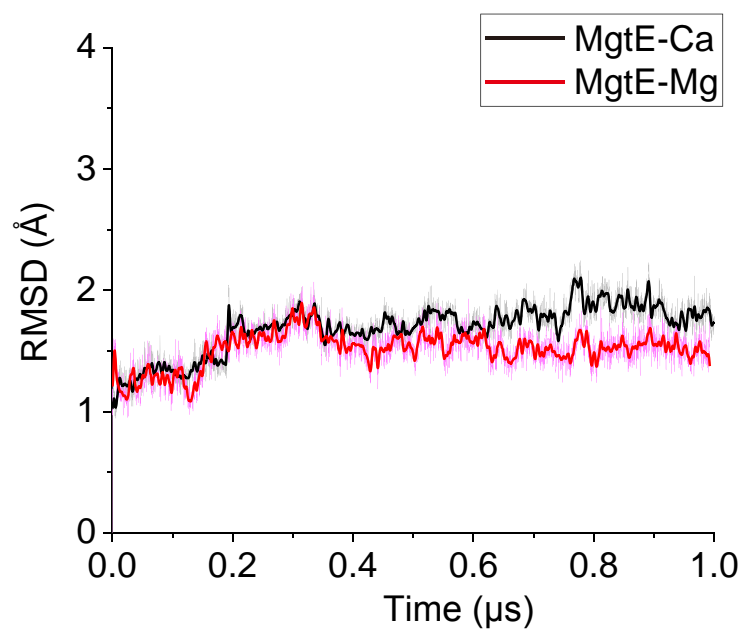

C

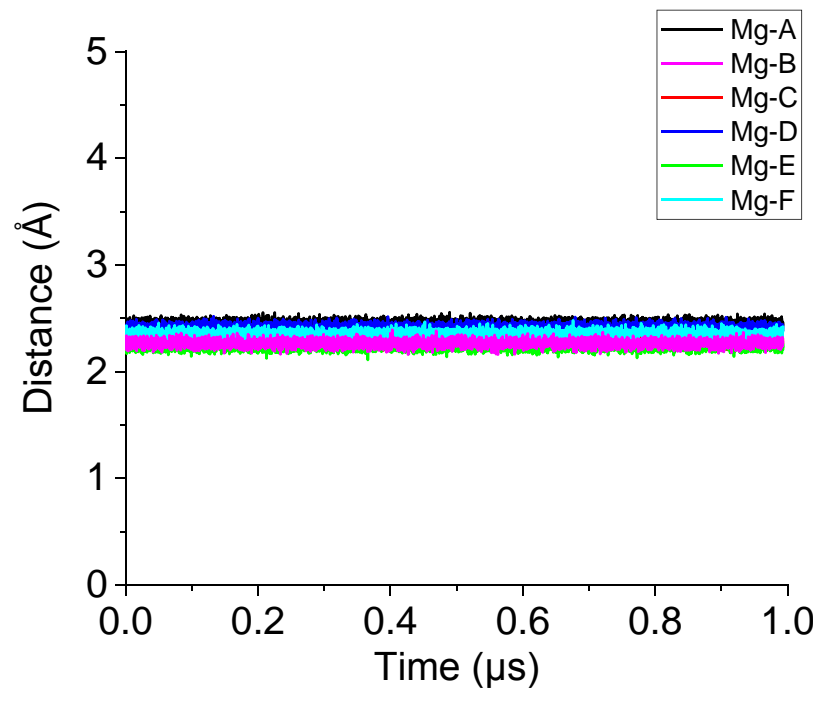

$\mathrm{B}$
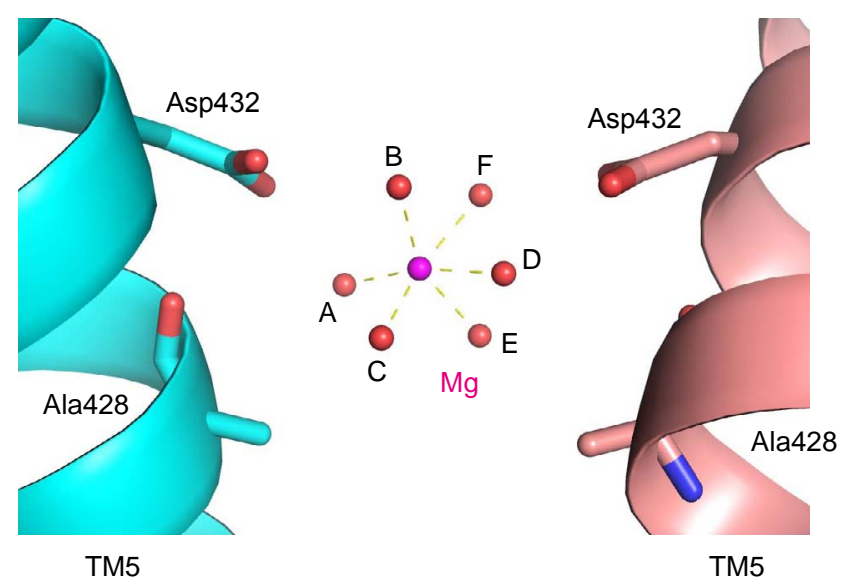

D

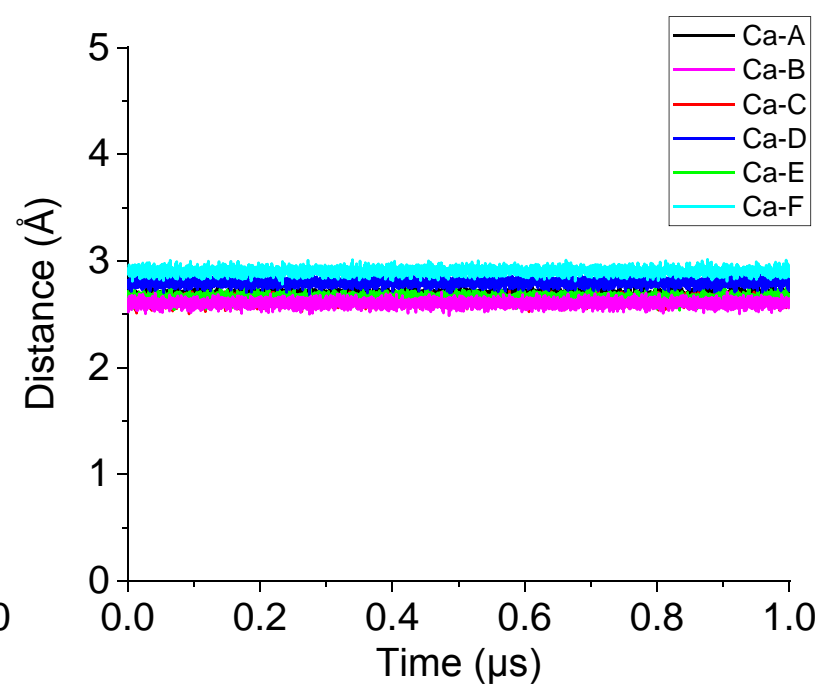

Figure 4 
Table $1 \mathrm{X}$-ray data collection and refinement statistics

MgtE TM with $\mathrm{Ca}^{2+}$

\begin{tabular}{|c|c|}
\hline Data collection & \\
\hline Wavelength $(\AA)$ & 1.000 \\
\hline Space group & $P 2_{1} 2_{1} 2_{1}$ \\
\hline Cell dimensions & \\
\hline$a, b, c(\AA)$ & $64.8,70.3,104.0$ \\
\hline$\alpha, \beta, \gamma\left(^{\circ}\right)$ & $90.0,90.0,90.0$ \\
\hline Resolution $(\AA)^{*}$ & $47.62-2.50(2.65-2.50)$ \\
\hline$R_{\text {merge }}{ }^{*}$ & $0.448(3.690)$ \\
\hline$I / \sigma I^{*}$ & $10.82(1.02)$ \\
\hline Completeness $(\%)^{*}$ & $99.9(100.0)$ \\
\hline Redundancy ${ }^{*}$ & $35.3(36.0)$ \\
\hline $\mathrm{CC}_{1 / 2}(\%)^{*}$ & $99.5(57.4)$ \\
\hline Refinement & \\
\hline Resolution $(\AA)$ & 2.5 \\
\hline No. reflections & 16972 \\
\hline$R_{\text {work } /} R_{\text {free }}$ & $0.232 / 0.259$ \\
\hline No. atoms & \\
\hline Protein & 2671 \\
\hline Ligand/ion & 65 \\
\hline Water & 91 \\
\hline B-factors & \\
\hline Protein & 69.21 \\
\hline Ligand/ion & 82.96 \\
\hline Water & 71.27 \\
\hline R.m.s deviations & \\
\hline Bond lengths $(\AA)$ & 0.005 \\
\hline Bond angles $\left({ }^{\circ}\right)$ & 1.194 \\
\hline Ramachandran plot & \\
\hline Favoured (\%) & 100.0 \\
\hline Allowed (\%) & 0.0 \\
\hline Outliers (\%) & 0.0 \\
\hline
\end{tabular}

*Highest resolution shell is shown in parenthesis. 